\section{Flowering of Eucrosia Influenced by Bulb Size and Watering Frequency}

\author{
Mark S. Roh \\ U.S. Department of Agriculture, Agricultural Research Service, Florist \\ and Nursery Crops Laboratory, Beltsville, MD 20705
}

\section{Alan W. Meerow \\ University of Florida, Institute of Food and Agricultural Sciences, Research and Education Center, Ft. Lauderdale, FL 33314}

Additional index words. South American bulb, Amaryllidaceae, dormancy, Eucrosia bicolor

Eucrosia Ker Gawler (Amaryllidaceae) is native to Ecuador and Peru and consists of seven species (Meerow, 1987). They produce bulbs and are endemic primarily to seasonally dry regions of the lower, western Andean slopes and Pacific coastal lowlands. In nature, the scape emerges before the leaves, which are elliptic and petiolate. The red flowers are zygomorphic with long, delicate, yellow stamens that are fused into a staminal cup (Fig. 1).

Eucrosia bicolor var. bicolor has potential as a cut flower. Neither the environmental requirements for flowering nor the minimum bulb size or circumference that can be forced has been determined. Based on research with Hippeastrum hybridum Hort. (Boyle and Stimart, 1987), an experiment was conducted to test the effect of controlled irrigation on flowering and to determine the minimum bulb size for flowering.

Six bulbs of E. bicolor $(<3 \mathrm{~cm}$ in circumference) were planted in 2.6-liter pots containing a sterilized growing medium composed of 3 soil : 4 perlite : 4 peatmoss (by volume, $\mathrm{pH}=6.4$ ). Plants were grown in a greenhouse maintained at a night minimum of $21 \mathrm{C}$ and fertilized weekly with $200 \mathrm{ppm} \mathrm{N}$ from a 20N-8.6P-11.4K fertilizer (Peters 20-2020; Grace-Sierra, Allentown, Pa.) in 198688. Plants were transplanted into 3.8-liter pots

Received for publication 8 Aug. 1991. Accepted for publication 14 June 1992. We thank Thomas $\mathrm{H}$. Boyle for reading the manuscript. The cost of publishing this paper was defrayed in part by the payment of page charges. Under postal regulations, this paper therefore must be hereby marked advertisement solely to indicate this fact. on 31 Mar. 1988. Plants were grown in a greenhouse maintained at a night minimum (NT) of 16C until harvest on 17 Oct. 1988. Day temperatures (DT) ranged from 26 to 35C.

All plants were watered on 15 and 30 Aug. 1988; subsequently, the plants were watered as follows: 1) none (A); 2) 15 Sept. (B); 3) 15 Sept. and 1 Oct. (C); and 4) 15 Sept. and 1 and 15 Oct. (D and E). There were three pots per treatment.

After bulb harvest, al! roots and leaves were removed and bulbs were stored dry at $20 \mathrm{C}$ for 30 days (A-D) or 60 days (E). Bulbs were replanted, one bulb per 1.6-liter pot, on 17 Nov. 1988. Plants were grown in a greenhouse maintained at $21 / 16 \mathrm{C}$ (DT/NT) until flowering.

A completely randomized design was employed using a minimum of 17 bulbs per treatment, each weighing $>16 \mathrm{~g}(>8.1 \mathrm{~cm}$ in circumference). Dates of leaf and inflorescence emergence were recorded and, at flowering, the number of flower buds and scape length from the nose of bulb to the base of the umbel were recorded. Days to flowering were counted from 15 Aug. 1988. Means were compared by Duncan's multiple range test.

Due to a great variation in flowering time, especially when the controlled watering treatments were started early (A and B), watering treatments had no significant effect on days to flower (Table 1), flower count (6.7-7.9), and scape length $(36-42 \mathrm{~cm})$. Inflorescence emergence spanned 36 days and flowering 17 days. Time required from inflorescence emergence to flowering spanned 19 days (Table 1). Although one bulb that weighed $18 \mathrm{~g}$ (9.6 $\mathrm{cm}$ in circumference)

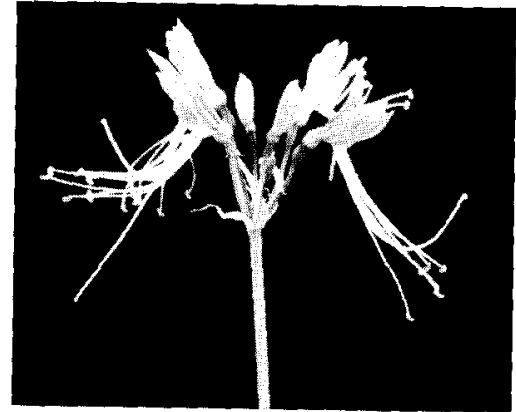

Fig. 1. Inflorescence of Eucrosia bicolor.

flowered, three bulbs that weighed $23 \mathrm{~g}$ (11.7 $\mathrm{cm}$ in circumference) did not flower (E). Small bulbs that did not produce an inflorescence took $>60$ days for leaf emergence. The minimum size of bulbs capable of flowering ranged from $21 \mathrm{~g}$ (10.7 $\mathrm{cm}$ in circumference) to $27 \mathrm{~g}(12.5 \mathrm{~cm}$ in circumference).

Microscopical dissection of E. bicolor did not reveal flower buds at harvest, which suggests that controlled watering did not induce or influence flower bud initiation in this experiment. Interruption of watering may not have been long enough to induce flowering or the bulbs may have been too small at harvest when watering was terminated on or before 15 Sept. (A and B). Flowering of Hippeastrum from mature bulbs resulted from rapid extension of the scape by irrigation interruption (Boyle and Stimart, 1987).

The lack of acceleration of flowering in bulbs stored for 60 days at 20C (E) suggests that $20 \mathrm{C}$ may not be an optimal temperature for flower bud initiation from small bulbs. The effect of the watering treatment may have been masked by the effect of root and leaf removal after bulb harvest plus dry storage at $20 \mathrm{C}$.

Since controlled watering and storing bulbs at 20C failed to ensure early flowering in $\boldsymbol{E}$. bicolor, it may be necessary to investigate the effect of temperature during vegetative growth before harvest in conjunction with controlled watering before bulb harvest. Anatomical work is needed to ascertain the presence of dormancy in relation to developmental stages of flower bud initiation.

\section{Literature Cited}

Boyle, T.H. and D.P. Stimart. 1987. Influence of irrigation interruptions on flowering of Hippeastrum $\times$ hybridum 'Red Lion'. HortScicnce 22(6):1290-1292.

Meerow, A.W. 1987. A monograph of Eucrosia (Amaryllidaceae). Syst. Bot. 12:460-492.

Table 1. Effect of watering and bulb size on flowering of Eucrosia bicolor.

\begin{tabular}{|c|c|c|c|c|c|c|c|}
\hline Trcatment & Watering dates ${ }^{z}$ & $\begin{array}{c}\text { Days at } \\
20 \mathrm{C} \\
\text { (no.) }\end{array}$ & $\begin{array}{c}\text { Bulbs }^{y} \\
\text { (no.) }\end{array}$ & \multicolumn{3}{|c|}{ No. days } & $\begin{array}{l}\text { Min. flowering } \\
\text { bulb size, wt }(\mathrm{g}) / \\
\text { circum. (cm) }\end{array}$ \\
\hline B & 15 Sept. & 30 & $8 / 17$ & $195 \mathrm{a}$ & $232 \mathrm{a}$ & $37 \mathrm{ab}$ & $24 / 11.8$ \\
\hline $\mathrm{C}$ & 15 Scpl., 1 Oct. & 30 & $12 / 17$ & $213 \mathrm{a}$ & $244 a$ & 31 a & $21 / 10.8$ \\
\hline $\mathrm{D}$ & $15 \mathrm{Scpt} ., 1 \mathrm{Oct}, 15 \mathrm{Oct}$. & 30 & $15 / 19$ & $219 a$ & $247 \mathrm{a}$ & $28 \mathrm{a}$ & $25 / 12.0$ \\
\hline
\end{tabular}

${ }^{\mathrm{z}}$ A: Watered only 15 and 30 Aug.; others on those dates as indicated.

${ }^{\mathrm{y}}$ Number of bulbs flowered/sample size.

xMean separation within columns by Duncan's multiple range test at $P=0.05$. 